\title{
Seroprevalence of Leptospirosis among Water Buffaloes, Pigs, and Dogs in Selected Areas in the Philippines, 2007 to 2008
}

\author{
Sharon Yvette Angelina M. Villanueva, ${ }^{1,2}$ Rubelia A. Baterna, ${ }^{2}$ Lolita L. Cavinta, ${ }^{2}$ \\ Yasutake Yanagihara, ${ }^{3}$ Nina G. Gloriani ${ }^{2}$ and Shin-ichi Yoshida ${ }^{1}$ \\ ${ }^{1}$ Department of Bacteriology, Faculty of Medical Sciences, Kyushu University, Fukuoka, Japan \\ ${ }^{2}$ Department of Medical Microbiology, College of Public Health, University of the Philippines Manila, Manila, Philippines \\ ${ }^{3}$ University of Shizuoka, Shizuoka, Japan
}

\begin{abstract}
Background. Domestic animals are known to be either maintenance or accidental hosts of Leptospira. Determination of seroprevalence of leptospirosis among these animals is of great importance due to their close association with humans, economic loss as well as the public and veterinary health problems caused by the said zoonosis.
\end{abstract}

Objective. This study aimed to determine the seroprevalence of leptospirosis among water buffaloes, pigs, and dogs in selected areas in the Philippines.

Methods. Microscopic agglutination test (MAT) was used to test for leptospirosis. Testing was done from January 2007 to August 2008.

Results. With the cut-off titer set at 1:80, the MAT-positivity rates were $82 \%, 67 \%$, and $79 \%$ for 190 water buffaloes, 45 pigs, and 106 dogs, respectively. The most common prevailing serovars detected were Hardjo, Tarassovi, and Hebdomadis for water buffaloes; Semaranga, Grippotyphosa, and Patoc for pigs; and, Manilae, Patoc, and Autumnalis for dogs. MAT-positivity rates among these animals in terms of age (except for water buffaloes), sex and sample collection sites were not statistically significant. No Leptospira was isolated from the blood, urine, and kidney samples of these animals.

Conclusion. Results indicate a high seroprevalence of leptospirosis among the animals studied and that several pathogenic leptospires are causing infection in these animals.

Key Words: seroprevalence, leptospirosis, water buffaloes, dogs, pigs, Philippines

\section{INTRODUCTION}

Part of the paper was presented at the College of Public HealthUniversity of the Philippines Manila/World Health OrganizationWestern Pacific Regional office/Kyushu University Joint Scientific meeting on Leptospirosis in the Asia Pacific Region, November 6-7, 2008; and at the 6th International Leptospirosis Society Meeting, September 21-24, 2009, Cochin, India.

Corresponding author: Sharon Yvette Angelina M. Villanueva, MMSc, PhD

Department of Medical Microbiology

College of Public Health

University of the Philippines Manila

625 Pedro Gil St., Ermita, Manila 1000 Philippines

Telephone: +632 5255874

Email:smvillanueva4@up.edu.ph
Leptospirosis is a zoonosis that can infect humans as well as various wild and domestic animals, ${ }^{1-3}$ which may serve either as maintenance or accidental hosts of this infection. ${ }^{3,4}$ Maintenance hosts, especially rats, do not develop clinical signs of leptospirosis but spread the organisms usually through their urine thereby infecting humans and other animals (accidental hosts) directly or indirectly through contaminated environment. ${ }^{3-7}$ Leptospirosis can cause problems in human and animal health as well as in livestock industry resulting in economic loss and health hazards especially to animal handlers. ${ }^{1,8}$ The presence of this infection especially in domestic animals has been previously reported $^{1,2,4,7,9-15}$ but are outdated in the Philippines, the last being published in $1986 .^{16}$ 
Humans and domestic animals (i.e., dogs, cattle and swine) suffer from systemic disease due to leptospirosis. Leptospirosis in humans has a variety of manifestations ranging from a mild, influenza-like illness to severe infection affecting renal, hepatic and pulmonary functions, and may even cause death. ${ }^{3,4}$ Similar to humans, the clinical signs of leptospirosis in animals are also varied ranging from acute to subacute and chronic infection. ${ }^{3}$ Around 3-7 days after infection, acute leptospirosis usually develops and is similar in all animals wherein they experience anorexia, fever, irritability, ruffled fur, lethargy, etc. ${ }^{1}$ Infertility and reproductive failure among bovines (i.e., cattle and water buffaloes) and swine are usually associated with leptospirosis. ${ }^{1}$ Leptospirosis is presented as a severe disease, even causing death, among the calves, feeders and piglets. ${ }^{1,11}$ There are four pathological manifestations of leptospirosis reported in dogs namely icterus, hemorrhage, uremia (Stuttgart disease) and perinatal disorder (abortion and birth of premature or weak pups)., ${ }^{5,7}$ The clinical signs in animals are thought to be associated with host-adapted serovars such as Canicola in dogs; Pomona and Bratislava in horses and pigs; Hardjo in cattle; and, Australis and Pomona in pigs. ${ }^{3,5,17}$

Seroepidemiological studies are very important in order to gain knowledge on the different prevailing serovars and their maintenance hosts in any given area. Knowledge from these studies are important especially in the formulation of preventive and control measures against leptospirosis. Our study aimed to present an update on the distribution of leptospirosis in terms of the prevailing Leptospira serovars among water buffaloes, pigs, and dogs. We further aimed to determine the distribution of leptospirosis in terms of age, sex and location of these animals.

\section{METHODS}

The serosurvey was conducted among the most common and important domestic animals in the Philippines. Water buffaloes, carabaos in particular, are the most important farming animals in the Philippines ${ }^{12}$ and in other countries $^{1,10,18}$ since they are used as labor animals and sources of meat and milk (personal communications with the staff of Philippine Carabao Center, Nueva Ecija). Pigs are the important sources of meat ${ }^{1}$ while dogs are common pets or companion animals.

\section{Sampling, collection sites and animal samples}

Anti-Leptospira antibodies and/or isolation of leptospires in humans ${ }^{19-21}$ and animals, especially rats, ${ }^{22,23}$ were previously reported in the Philippines. From January 2007 to August 2008, blood, urine, and if available, kidney samples were obtained from water buffaloes, pigs, and dogs in selected areas in the country. The blood, urine, and kidney samples were used for isolation of leptospires while the sera were used for the microscopic agglutination test (MAT).
Blood samples were obtained from the jugular veins (pigs and water buffaloes) or leg veins (dogs) and stored in sterile tubes. For slaughtered animals (i.e., pigs), urine was collected directly by puncturing the urinary bladder with sterile syringe. For dogs and water buffaloes, urine was collected when freshly voided or by using sterile catheter. Kidneys of the pigs were collected after they were slaughtered and were placed in clean plastic bags immediately after extraction. When available, kidneys were collected from the dogs in a similar way as for pigs.

\section{Sample Collection in Water buffaloes}

Samples from water buffaloes were collected from a slaughterhouse in Pasay City and in several areas in the province of Nueva Ecija (i.e., Muñoz, Licaong, San Jose, Llanera, and Talavera). Nueva Ecija is a province located in the Luzon island. The water buffaloes in the slaughterhouse came from farms in Batangas and Masbate, which are also both located in the Luzon island, and Cagayan de Oro, which is located in the Mindanao island.

The water buffaloes were placed in chutes during blood extraction in order to fix the animals and prevent unnecessary movements that may harm them during the process. Vitamins and anti-helminthics were administered to these animals after blood extraction.

\section{Sample Collection in Pigs}

Pig samples were obtained from a slaughterhouse in Pasay City (Metro Manila). These pigs were porkers whose meats were scheduled to be distributed in markets for selling and consumption. The sources of these pigs were piggeries in Bulacan, Batangas, Cavite, and General Santos City. The first 3 provinces are located in the Luzon island while the latter is located in the Mindanao island.

\section{Sample Collection in Dogs}

Dog samples were obtained from dog pounds located in the major cities of Metro Manila namely Manila, Quezon City, and Makati City. These were stray dogs that were captured as part of the city ordinances of these 3 cities on responsible pet ownership. In these city ordinances, stray animals that are impounded shall stay within the City Pounds for 3 or more days until they are claimed by the owners or until they are adopted by new owners. If left unclaimed or unadopted within 2 weeks, they will be euthanized.

\section{Determination of anti-Leptospira antibodies and prevailing serovars through the MAT}

A battery of 17 live leptospires representing reference serovars and local (Philippine) isolates were used in the MAT, the procedures of which was based on the World Health Organization - International Leptospirosis Society guidance on leptospirosis ${ }^{3}$ and a previous study on rats. ${ }^{23}$ The leptospires used were Leptospira interrogans serovars Manilae 
(strain LT 398), Pyrogenes (strain Salinem), Canicola (strain Hond Utrecht IV), Autumnalis (strain Akiyami A), Losbanos (strain LT 101-69), Hebdomadis (strain Akiyami B), Australis (strain Akiyami C), Copenhageni (strain M20), Icterohaemorrhagiae (strain Ictero No. 1), Pomona (strain Pomona), and Hardjo (strain Hardjoprajitno); L. borgpetersenii serovars Tarassovi (strain Perepelitsin) and Poi (strain Poi); L. kirschneri serovars Ratnapura (strain UPBL-FR13) and Grippotyphosa (strain Moskva V); L. meyeri serovar Semaranga (strain Veldrat Semaranga 173); and, L. biflexa serovar Patoc (strain Patoc 1). Serovars Manilae, Losbanos and Ratnapura are isolates from the Philippines. Briefly, serum samples were reacted with the leptospires for $2-4$ hours at $30^{\circ} \mathrm{C}$ incubator. Sera that had $50 \%$ or more agglutination compared to the free leptospires at reciprocal titers of $\geq 80$ were considered MAT-positive or seropositive. The serovar that induced the highest titer was considered to be the presumptive infecting serovars. ${ }^{13,24}$ Those sera that had the highest titer with only 1 serovar were classified as infected with "single Leptospira serovar" (represented by Arabic numbers in Tables 1 to 3 ) but if the same highest titers were found in two or more serovars then infection was considered to be probably caused by "multiple serovars" (represented by letters in Tables 1 to 3). ${ }^{25}$ Sera that did not react with any of the antigens used or that reacted at titers lower than 1:80 were considered MAT-negative.

\section{Isolation of leptospires}

Blood and, if available, urine and kidneys of the different animals were cultured in 5-fluorouracil (5-FU)-containing modified Korthof's medium supplemented with $10 \%$ rabbit serum.

\section{Blood and urine samples}

Blood and urine samples were separately cultured in 4 tubes containing $4 \mathrm{~mL}$ media each, ${ }^{23}$ One, 2 , and 3 (2 tubes) drops of blood and urine samples were cultured in these tubes. The cultures were incubated at $30^{\circ} \mathrm{C}$ incubator and were examined every week for 3 months.

\section{Kidney samples}

Kidneys were washed with sterile distilled water, soaked in ethanol and washed again with distilled water. Then, around $1-2 \mathrm{~cm}$ was sliced from the renal medulla, macerated with sterile syringe and cultured in the medium. The culture was then incubated overnight at $30^{\circ} \mathrm{C}$ incubator. The next day, 500 $\mu \mathrm{L}$ of the supernatant were transferred into fresh Korthof's medium and were cultured as in blood and urine samples.

\section{Animal ethics}

Written permissions were obtained from the heads of the institutions where the animal samples were obtained. Oral consent was also obtained from the farmers or owners of the water buffaloes after adequate explanation, delivered in the vernacular, of the purpose and mechanics of the current study.

\section{Statistical analysis}

Data encoding and analysis were done using Epi Info version 3.5.1. (Centers for Disease Control and Prevention, Georgia, U.S.A.) and STATA/SE 10.0 (STATA Corp., Texas, U.S.A.). The areas where the animals were reared were correlated with the MAT results, hence, the place of origin of the animals, not the location of the slaughterhouses, was considered for the statistical analysis of samples collected in slaughterhouses. Statistical differences in MAT-positivity rates of animals and different animal parameters like age, sex, and sample collection sites were analyzed using Chi-square $\left(\chi^{2}\right)$ test for homogeneity. $\mathrm{P}$ values $<0.05$ were considered to be statistically significant.

\section{RESULTS}

A total of 190 water buffaloes, 45 pigs, and 106 dogs were included in the study. The succeeding sections describe the results obtained from the different laboratory tests done on the samples obtained from these animals.

\section{Microscopic agglutination test (MAT)}

The MAT results of the serum samples from water buffaloes, pigs and dogs are presented in Tables 1 to 3, respectively. Animal sera that reacted with single Leptospira serovars are shown in Arabic numbers while those that reacted with multiple serovars are shown in alphabets (i.e., one animal represents one alphabet). The total (written in bold Arabic numbers) is the combined reactions to the single and multiple serovars.

\section{Water buffaloes}

Of the 190 water buffalo serum samples, 155 (82\%) were found to have antibodies against the panel of leptospires used in this study with titers ranging from 1:80 to 1: 5,120 (Table 1). Majority of the water buffaloes were reactive to serovars Hardjo (38), Tarassovi (32), and Hebdomadis (24). Five water buffaloes had reciprocal titers as high as 5,120, which were against Hardjo (2), Tarassovi (1), and Pomona (2). Eleven of the water buffaloes were found to be infected with multiple serovars. No sera reacted with serovars Canicola and Poi.

Pigs

Thirty pig sera (67\%) were found to be MAT-positive (Table 2). The antibody titers detected were between 1:80 and 1:320. The pigs were mostly reactive to serovars Semaranga (9), Grippotyphosa (6), and Patoc (5). The highest titer (i.e., 1:320) was against Semaranga (5), Autumnalis (1), and Manilae (1). Four of the reactive sera were against multiple Leptospira serotypes. One pig serum did not singly react with serovar Copenhageni (serogroup Icterohaemorrhagiae) 
Table 1. Microscopic agglutination test (MAT) result of water buffalo serai $(n=190)$

\begin{tabular}{|c|c|c|c|c|c|c|c|c|}
\hline \multirow{2}{*}{ Serovar } & \multicolumn{7}{|c|}{ No. of sera showing the following agglutination titers } & \multirow{2}{*}{ Total no. of + ve } \\
\hline & 80 & 160 & 320 & 640 & 1,280 & 2,560 & 5,120 & \\
\hline Hardjo & 2 & c & 10,g,h,i & 3 & 6 & $10, \mathrm{k}$ & 2 & 38 \\
\hline Tarassovi & $1, a, b$ & $6, c$ & $6, f$ & 7 & $5, \mathrm{j}$ & 1 & 1 & 32 \\
\hline Hebdomadis & 3 & 1 & $6, g$ & 5 & $3, j$ & $3, \mathrm{k}$ & & 24 \\
\hline Patoc & $4, a, b$ & 5 & 3 & 1 & & & & 15 \\
\hline Pomona & 2 & $1, e$ & 2 & 4 & 2 & 1 & 2 & 15 \\
\hline Ratnapura & & 2 & 2 & 3 & 2 & & & 9 \\
\hline Semaranga & 3 & 2,e & 3 & & & & & 9 \\
\hline Manilae & & $1, \mathrm{~d}$ & 3 & 1 & & & & 6 \\
\hline Pyrogenes & & d,e & $2, \mathrm{~h}, \mathrm{i}$ & & & & & 6 \\
\hline Losbanos & & & $1, \mathrm{f}$ & 2 & & & & 4 \\
\hline Australis & & & 2 & & 1 & & & 3 \\
\hline Grippotyphosa & $b$ & 1 & 1 & & & & & 3 \\
\hline Autumnalis & 1 & 1 & g & & & & & 3 \\
\hline Icterohaemorrhagiae & $1, a$ & $d$ & & & & & & 3 \\
\hline Copenhageni & 1 & & & & & & & 1 \\
\hline Canicola & & & & & & & & 0 \\
\hline Poi & & & & & & & & 0 \\
\hline Total & & & & & & & & $171^{\mathrm{iii}}$ \\
\hline
\end{tabular}

Sera that reacted with single serovar are shown in Arabic numbers while those reacting with multiple serovars are shown in alphabets. Each alphabet represents 1 water buffalo serum. The number of MAT-negative sera was 35.

ii Number of animals having antisera to corresponding serovars.

iii Number of MAT-positive water buffaloes was 155. One hundred forty-four were positive to single serovar while 11 were positive to multiple serovars thus the total was 171.

Table 2. Microscopic agglutination test (MAT) result of pig serai $(n=45)$

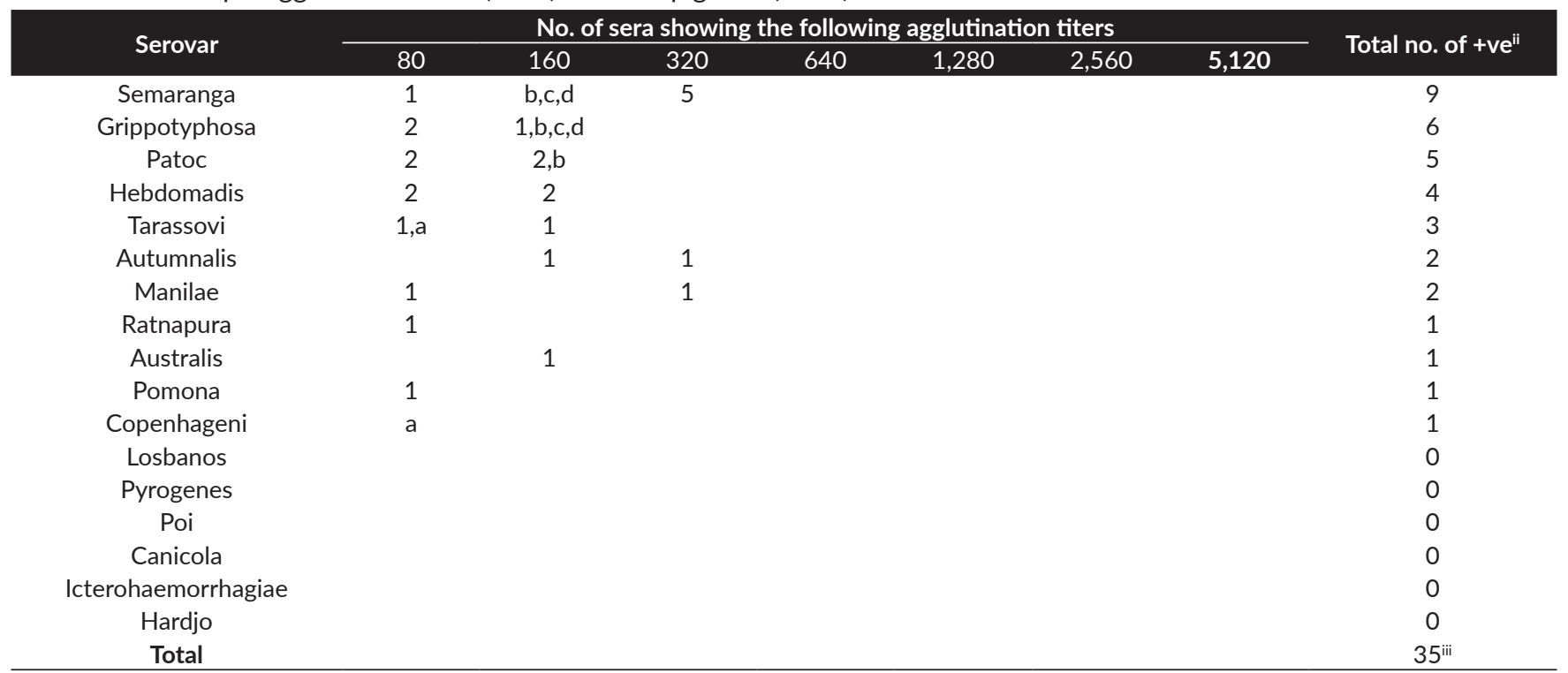

i Sera that reacted with single serovar are shown in Arabic numbers while those reacting with multiple serovars are shown in alphabets. Each alphabet represents 1 pig serum. The number of MAT-negative sera was 15.

ii Number of animals having antisera to corresponding serovars.

iii Number of MAT-positive pigs was 30. Twenty-six were positive to single serovar while 4 were positive to multiple serovars thus the total was 35.

but was found to be in combination with serovar Tarassovi (serogroup Tarassovi) at a titer of 1:80.

\section{Dogs}

Eighty six of the 109 (79\%) dog sera had antibodies against the panel of antigens used in MAT (Table 3). The most common infecting serovars found in dogs were Manilae (22), Patoc (16), and Autumnalis (12). Similar to water buffaloes, the antibody titers detected in dogs ranged from 1:80 to 1:5, 120. Three of the dog sera had the highest reciprocal titer of 5,120, which were all against Manilae. Seventeen dog sera were reactive against multiple serotypes. Furthermore, serovar Pyrogenes (serogroup Pyrogenes) did not singly react with any of the sera but in combination with serovar Manilae, belonging to the same serogroup, at titers of 1:80 and 1:320 (1 each). Also, serovar Icterohaemorrhagiae was 
Table 3. Microscopic agglutination test (MAT) result of dog serai $(n=109)$

\begin{tabular}{|c|c|c|c|c|c|c|c|c|}
\hline \multirow{2}{*}{ Serovar } & \multicolumn{7}{|c|}{ No. of sera showing the following agglutination titers } & \multirow{2}{*}{ Total no. of + ve } \\
\hline & 80 & 160 & 320 & 640 & 1,280 & 2,560 & 5,120 & \\
\hline Manilae & $2, a, f$ & $1, \mathrm{i}, \mathrm{k}$ & $5, \mathrm{~s}$ & 3 & 1 & 2 & 3 & 22 \\
\hline Patoc & 6 & 2,g,h,j,m & $2, q, r$ & & & & & 16 \\
\hline Autumnalis & 3,b,e & $4, \mathrm{j}, \mathrm{n}$ & 1 & & & & & 12 \\
\hline Copenhageni & 3,a,d,e & $1, \mathrm{i}, \mathrm{k}$ & 1 & 1 & & & & 11 \\
\hline Grippotyphosa & $1, a, b$ & 1,g,h & $3, p, r$ & & & & & 11 \\
\hline Semaranga & $\mathrm{c}, \mathrm{e}$ & $4, \mathrm{j}, \mathrm{m}, \mathrm{n}$ & $\mathrm{q}$ & & & & & 10 \\
\hline Losbanos & & 3 & 1 & & 1 & 2 & & 7 \\
\hline Pomona & 1 & & $1, p, r$ & & 1 & & & 5 \\
\hline Hebdomadis & 1 & 3 & & & & & & 4 \\
\hline Pyrogenes & $f$ & & $1, \mathrm{~s}$ & & & & & 3 \\
\hline Poi & & & 1 & 2 & & & & 3 \\
\hline Tarassovi & & 1 & & & & & & 1 \\
\hline Icterohaemorrhagiae & $d$ & & & & & & & 1 \\
\hline Hardjo & c & & & & & & & 1 \\
\hline Canicola & & & & & & & & 0 \\
\hline Australis & & & & & & & & 0 \\
\hline Ratnapura & & & & & & & & 0 \\
\hline Total & & & & & & & & $107^{\mathrm{iii}}$ \\
\hline
\end{tabular}

i Sera that reacted with single serovar are shown in Arabic numbers while those reacting with multiple serovars are shown in alphabets. Each alphabet represents 1 dog serum. The number of MAT-negative sera was 23.

"Number of animals having antisera to corresponding serovars.

iii Number of MAT-positive dogs was 86. Sixty-nine were positive to single serovar while 17 were positive to multiple serovars thus the total was 107.

in combination with serovar Copenhageni at a titer of 1:80, both of which belong to serogroup Icterohaemorrhagiae. One dog serum reacted with serovar Hardjo (serogroup Sejroe) and serovar Semaranga (serogroup Semaranga) at 1:80 titer, though these serovars belong to different serogroups.

\section{MAT-positivity rates in relation to animal demographics}

Age

The age of the water buffaloes, pigs, and dogs in the slaughterhouses and dog pounds were unknown to the veterinarians and animal handlers so the said data were not obtained. The only available data on age were those of the water buffaloes in the province of Nueva Ecija. Results showed that compared to the younger water buffaloes, older ones ( 3 years old and above) had the highest MAT-positivity rate, which was $44 \%$ (Table 4 ). This difference was statistically significant $\left(\chi^{2}\right.$ test $\left.=28.99 ; \mathrm{p}=0.0001\right)$.

\section{Sex}

Table 5 summarizes the prevalence rates of leptospirosis among the different animals in terms of sex. Female water buffaloes had a higher positivity rate (80\%) compared to the males (63\%). Similarly, female dogs were found to be more infected (81\%) compared to males (77\%). In contrast, male pigs were found to have higher positivity rate (75\%) compared to female pigs (46\%). However, the differences in the MAT-positivity rates of these animals in terms of sex were not statistically significant $\left(\chi^{2}\right.$ test $=2.58, p=0.11$ for water buffaloes; $\chi^{2}$ test $=3.46, \mathrm{p}=0.06$ for pigs; and, $\chi^{2}$ test $=$ $0.21 ; \mathrm{p}=0.65$ for dogs).
Table 4. Age-specific MAT-positivity rates among water buffaloes in the Philippines

\begin{tabular}{ccc} 
Age (in years) & \# of sample & \# of MAT-positive (\%) \\
0 & 22 & $15(12)$ \\
1 & 43 & $24(20)$ \\
2 & 36 & $29(24)$ \\
$\geq 3$ & 53 & $53(44)$ \\
Total & 154 & 121 \\
\hline
\end{tabular}

iThe total number of water buffaloes was 190 but 36 had unknown age.

Table 5. Prevalence rates of leptospirosis among different types of animals in the Philippines by sex

Animal Sex \# of sample \# of MAT-positive (\%)

\begin{tabular}{llcc} 
Water buffalo & Bothi $^{\text {i }}$ & 190 & $155(78)$ \\
& Male & 19 & $12(63)$ \\
& Female & 137 & $109(80)$ \\
\hline Pig & Both & 45 & $30(67)$ \\
& Male & 32 & $24(75)$ \\
& Female & 13 & $6(46)$ \\
\hline \multirow{2}{*}{ Dog } & Both & 109 & $86(79)$ \\
& Male & 57 & $44(77)$ \\
& Female & 52 & $42(81)$
\end{tabular}

iThe sex of 34 water buffaloes was unknown.

\section{Sample collection sites}

One hundred per cent positivity rate was observed among water buffaloes from Cagayan de Oro, Masbate, Batangas, and from the cities of San Jose and Llanera of Nueva Ecija, followed by a $76 \%$ and $75 \%$ positivity rate from the Nueva Ecija cities of Muñoz and Licaong, respectively (Table 6). However, there was no statistically significant difference in the MAT-positivity rates of the water buffaloes according to the sample collection sites $\left(\chi^{2}\right.$ test $\left.=10.11 ; \mathrm{p}=0.18\right)$. 
Table 6. Prevalence rates of leptospirosis among water buffaloes, pigs, and dogs in the Philippines by sample collection site

\begin{tabular}{lcc}
\hline Animal and collection site & \# of sample & \# of MAT-positive (\%) \\
A. 190' water buffaloes & 7 & $7(100)$ \\
Cagayan de Oro & 3 & $3(100)$ \\
Masbate & 4 & $4(100)$ \\
Batangas & 7 & $7(100)$ \\
San Jose, Nueva Ecija & 10 & $10(100)$ \\
Llanera, Nueva Ecija & 103 & $78(76)$ \\
Muñoz, Nueva Ecija & 16 & $12(75)$ \\
Licaong, Nueva Ecija & 20 & $14(70)$ \\
Talavera, Nueva Ecija & 170 & $135(79)$ \\
Total & & \\
B. 45 pigs & 22 & $18(82)$ \\
Bulacan & 10 & $6(60)$ \\
General Santos City & 12 & $6(50)$ \\
Batangas & 1 & $0(0)$ \\
Cavite & 45 & $30(67)$ \\
Total & & \\
C. 109 dogs & 31 & $25(81)$ \\
Manila & 76 & $60(79)$ \\
Makati & 2 & $1(50)$ \\
Quezon City & 109 & $86(79)$ \\
Total &
\end{tabular}

iTwenty had unknown sample collection site.

As shown in Table 6, pigs in Bulacan had the highest MAT-positivity rate (82\%) followed by General Santos City (60\%) then Batangas (50\%). However, there was no statistically significant difference observed among these sample collection sites $\left(\chi^{2}\right.$ test $\left.=5.84 ; \mathrm{p}=0.12\right)$.

Stray dogs in the city of Manila were found to have the highest positivity rate (81\%) followed by Makati (79\%), then Quezon City (50\%) (Table 6). Similar to the results of water buffaloes and pigs, the difference in the positivity rates in stray dogs based on sample collection sites was also not statistically significant $\left(\chi^{2}\right.$ test $\left.=1.05 ; \mathrm{p}=0.59\right)$.

\section{Isolation of leptospires}

No leptospires were isolated from the blood, urine and kidneys of all the animals in this study (data not shown).

\section{DISCUSSION}

Leptospirosis is of medical and veterinary importance. ${ }^{15}$ Infected humans as well as animals present with either acute or severe illness that may lead to death especially if not promptly diagnosed and treated., ${ }^{3,4}$ Results of our study revealed a high leptospirosis seroprevalence among the domestic animals caused by different Leptospira serovars. Since these animals are in close association with humans and other animals, the transmission of infection, at least within the collection sites, is very possible.

The MAT-positivity rate of water buffaloes in this study was $82 \%$, majority of which were reactive to serovars Hardjo, Tarrasovi, and Hebdomadis. Previous studies report varying
MAT-positivity rates (7.9 - 74\%), and antibodies against serovars Tarassovi, Sejroe, Hardjo, Pyrogenes, Pomona, and Grippotyphosa were found in carabao sera. ${ }^{12,16,26}$ The almost similar results (MAT-positivity and infecting serovar) observed between our study and the previous studies on leptospirosis among water buffaloes in the Philippines prove the persistence of infection caused by similar Leptospira serovars (i.e., Tarassovi, Hardjo, Pyrogenes, etc.) in the country over the years. A study by Bahaman et al. (1987) ${ }^{11}$ on leptospirosis in domestic animals in West Malaysia, also an Asian country like the Philippines, showed that the prevalence of leptospirosis among water buffaloes was low (31\%), but similar to the results of our study and previous studies on leptospirosis among water buffaloes, also reported serovars Hardjo and Tarassovi as the major infecting serovars among water buffaloes in West Malaysia. The serovars detected in our study as well as in previous reports in the Philippines and West Malaysia are known to be associated with bovine (i.e., cattle, buffaloes, etc.) leptospirosis. ${ }^{1}$ In other countries like Trinidad, water buffaloes were found to have antibodies against serovars Copenhageni, Georgia, Patoc and Bratislava. ${ }^{10}$ Some of the leptospires included in the MAT panel of antigens in our study and these studies are different therefore antibodies against these different serovars were not detected. ${ }^{10,12}$ This, however, does not exclude the possibility of the existence of infections caused by the undetected leptospires in the Philippines. The difference in the positivity rates in previous studies and this study may be attributed to the difference in sample size or due to difference in environmental conditions especially in different geographical locations. It may also be possibly due to the difference in MAT cut-off titers, which vary per region or country depending on the endemicity of leptospirosis. ${ }^{3}$ The selection of leptospires to be included in the MAT panel of antigens is also important in order to minimize false negative results due to the exclusion of possible infecting serovars. Therefore, the MAT-negativity in some of the animals tested in our study may either be due to non-infection or early stage infection or infection with leptospires not included in our MAT panel of antigens. ${ }^{3,10,13,23}$

The MAT-positivity among the pigs was $67 \%$, which was higher compared to a study done in West Malaysia (16.1\%). ${ }^{11}$ Serovars Pomona, Tarassovi, Bratislava and Grippotyphosa are the most common serovars causing swine leptospirosis. ${ }^{1}$ In our present study serovars Semaranga, Patoc, Hebdomadis and Grippotyphosa were found to be commonly affecting the pigs (Table 2). Basaca-Sevilla et al. (1986) ${ }^{16}$ detected anti-Grippotyphosa, Pomona, Autumnalis and Cynoptera antibodies in pigs' sera in the Philippines. In a similar study among pigs in neighboring West Malaysia, ${ }^{11}$ antibodies against similar serovars (i.e., Pomona, Icterohaemorrhagiae and Tarassovi) were also detected.

There was a $79 \%$ seropositivity rate observed among the dogs included in our study. Manilae, Patoc and Autumnalis were found to be the most common serovars affecting the 
dogs. Previous reports have shown that dogs are often infected with serovars Canicola, Icterohaemorrhagiae, and recently with Pomona, Grippotyphosa and Bratislava. ${ }^{1,7,13}$ It is, therefore, surprising that none of the $109 \mathrm{dog}$ sera reacted with Canicola, which is the most common Leptospira serovar associated with dogs. However, we do not exclude the possibility of Canicola-caused infections in dogs that were not included in our study. Some of the dog sera, however, reacted with serovars Icterohaemorrhagiae, Pomona, and Grippotyphosa. Adesiyun et al. (2006) ${ }^{9}$ also had similar results, wherein dogs included in their study did not have antibodies against serovar Canicola but had antibodies against serovar Icterohaemorrhagiae.

Detected antibodies may either be due to past or present infection or due to vaccination, $3,13,14,24$ making it necessary to correlate MAT results with the presence of clinical signs of leptospirosis as well as the vaccination history and epidemiological data of the animals.,7 Previous studies have reported that high MAT titers may imply current infection ${ }^{9}$ or may imply acute leptospirosis or active chronic infection. ${ }^{7,13}$ Vaccination may affect the results of MAT because it also elicits antibody production among vaccinated animals but antibody titers due to vaccination are usually low. ${ }^{7}$ Furthermore, vaccines, generally, do not induce high levels of agglutinating antibodies for more than several weeks therefore a high MAT titer among unvaccinated animals and no (or low) titers among vaccinated animals combined with clinical signs of leptospirosis must be considered highly suggestive of active infection. ${ }^{13}$ Therefore, the high titers that we observed among the animals, especially among dogs and water buffaloes may be indicative of current leptospirosis infection. On the other hand, the low MAT titers observed in some of the animals included in this study may be misconstrued as due to their vaccination. In the Philippines, there are anti-Leptospira vaccines that are available in the market but these vaccines are usually in combination with vaccines against other diseases and are expensive (personal communications with staff of city dog pounds). The authors do not also have information on whether this is actually being practiced by the people especially on domestic animals. Furthermore, except for the non-vaccination of the water buffaloes in Nueva Ecija (personal communications with the staff of Philippine Carabao Center, Nueva Ecija), we do not have any information on the vaccination status of the animals that were used in our current study. We, therefore, cannot conclude if the low titers observed in some of the animal sera studied were actually due to vaccination or due to early infection or past infection.

It is usually difficult to discriminate between crossreactions and multiple infections by MAT. Cross-reactions are usually observed in MAT, ${ }^{3}$ especially among serovars belonging to the same serogroup such as the reactions to multiple serotypes that we observed in our study. Similar to the results of our study, some of the water buffaloes in a study done by Adesiyun et al. were also found to be positive to more than one Leptospira serovars. ${ }^{10}$ These cross-reactions can also be observed usually at the early stage of the disease, therefore for a more definitive diagnosis of leptospirosis, paired sera are usually required since antibodies against the real infecting serovar usually appear later during the course of the infection., 3 Paired serum samples are necessary in order to detect seroconversion or rising antibody titers from acute to convalescent sera. However, since the animals included in our study were kept in slaughterhouses, dog pounds, and farms, we were able to collect only single serum samples. The reactions to multiple serotypes observed in our study, especially those at higher titers (1:2,560 and 1: 5,120 in water buffaloes), may possibly be due to mixed infections. Another hypothesis is that the frequently observed crossreactions between serovars from the same serogroup are based on those observed using rabbits ${ }^{1}$, the reactions between serovars from different serogroups may therefore be possibly observed when other animal hosts are used for the production of antisera.

Results of our study also showed frequent reactions of the animal sera against serovars Patoc and Semaranga, which are known to be non-pathogenic or saprophytic leptospires and are found in the environment or as contaminants especially of clinical materials. ${ }^{1,3,27,28}$ These saprophytic strains (also termed as water strains) were previously reported to be agglutinated by patients' sera as well as animal sera such as those of guinea pigs, horses, dogs, et cetera. ${ }^{27,28}$ Although these serovars are known not to cause disease in humans or animals, the medical significance of these saprophytes is still unknown. ${ }^{3}$ The high antibody titers against these 2 serovars observed among the animals that we studied may be due to increasing amount of antigens or its proliferation in the host. Another possibility is the repeated exposure of these animals to leptospire-contaminated environments. Since the animals studied are able to move around freely in the environment, it is highly possible that they were exposed to Leptospiracontaminated environments (e.g., water buffaloes cooling their bodies in water or mud especially during hot days ${ }^{29}$ and pigs submerged in mud or soil). There is, therefore, a need to confirm the role of these supposedly non-pathogenic Leptospira serovars in the pathogenicity of certain serovars using laboratory animals such as golden Syrian hamsters.

In this study, there was no statistically significant difference observed in the MAT-positivity rates of water buffaloes, pigs, and dogs with respect to sex, age (except those of water buffaloes), and sample collection sites. In a study on leptospirosis in water buffaloes in Trinidad by Adesiyun et al. (2009), ${ }^{10}$ there was also no statistically significant difference in the seropositivity rate of these animals in terms of age and sex. However, in a study by Adesiyun et al. $(2006)^{9}$ on canine leptospirosis, there was a statistically significant difference observed in terms of age and sex.

It is also noteworthy that although no leptospires were isolated from any of the specimens collected from the water buffaloes, leptospiral $\mathrm{AaB}$ gene was detected in 25 of the 98 
urine samples from Nueva Ecija (unpublished data). The sequences of these genes were found to be similar to either L. borgpetersenii or to L. kirschneri. Due to the presence of leptospiral DNA, we presumed that water buffaloes may also possibly excrete pathogenic leptospires (i.e., L. borgpetersenii and L. kirschneri) in their urine. This finding suggests that, aside from rats, water buffaloes may also be possible transmission sources of leptospires to humans and other animals in the Philippines particularly in areas where the samples were collected.

The detection of antibodies against several Leptospira serovars shows that the water buffaloes, pigs, and dogs in selected areas in the Philippines are exposed to environments that favor the thriving of leptospires. Faine et al. $(1999)^{1}$ wrote that farm animals or rodents that are ecologically associated with domesticated or foraging herds of farm animals are the most important sources of leptospirosis. These animals may also be possible transmission sources of leptospirosis, not only among animals but also among humans, especially their handlers or the people who also live in close proximity to them. In a previous study by Villanueva et al. (2010), ${ }^{23}$ serovars Manilae and Losbanos, and serogroups Grippotyphosa and Javanica were isolated from kidneys of rats in the Philippines. In our present study, antibodies against these Leptospira serovars and serogroups were detected in the sera of the animals studied. Rats in the Philippines may therefore be the possible transmission sources of infection among these three groups of domestic animals in the country. In studies done by Famatiga (1971), ${ }^{19}$ Masuzawa et al (2001), ${ }^{30}$ and Yanagihara et al (2007), ${ }^{21}$ antibodies against serovars Manilae, Losbanos, Tarassovi, Poi, etc. were found in the sera of Filipinos. These antibodies were also detected in the sera of the animals that we studied. There is, therefore, a high possibility of transmission of infection among humans and animals in the Philippines.

Our study involved limited study areas as well as sample size. Therefore, a larger survey on humans and other animals and wider geographical areas is highly recommended. Further studies have to be performed to better elucidate the transmission cycle/dynamics of leptospirosis in the Philippines, and also to determine if the same leptospires found in the 3 groups of animals studied are the same as those found in human cases of leptospirosis.

In summary, results of our study revealed the Leptospira serovars infecting the domestic animals in selected study sites. These results may also suggest the possible involvement of these serovars in human leptospirosis in the Philippines. Our study also disclosed the distribution of leptospirosis in terms of different animal characteristics such as age, sex, and sample collection sites. To our knowledge, our study provided a recent update on leptospirosis on domestic animals in the Philippines. The knowledge on the circulating serovars in a certain geographic area is very important especially in the formulation of preventive and control measures against leptospirosis, such as vaccines, that would help in alleviating problems on leptospirosis.

\section{Acknowledgments}

We are very grateful to the following people especially for their advice and technical support in the sample collection: Dr. Nobuo Koizumi of the National Institute of Infectious Diseases, Japan; Dr. Alice Alma C. Bungay, Mr. Rolando Villanueva, Mr. Victorino Franco, and Mr. Patricio Diaz of the Department of Medical Microbiology, College of Public Health, University of the Philippines Manila; Dr. Libertado Cruz, Dr. Aurelio Abesamis, Jr., Dr. Daniel Aquino, Dr. Nancy Abes, Dr. Lester Verona, Mr. Mario Delizo, and Ms. Charito Gutierrez of the Philippine Carabao Center in Nueva Ecija; Dr. Ma. Vivien Manalastas, Dr. Jasmin Oliver, and staff of the Makati City Veterinary Office; Dr. Manuel Socorro and staff of the Manila City Pound; Dr. Ana Maria Cabel and staff of The Veterinary Services of Quezon City Health Department, Dr. Ronaldo Bernasor and staff of the Pasay City Veterinary Office; Mr. Romulo Gutierrez and staff of Kayang Abattoir. We also express our sincerest gratitude to all the farmers in Nueva Ecija who were kind enough to allow us to collect samples from their water buffaloes. We are also very grateful to Prof. Suminori Kono of the Department of Public Health, Kyushu University (Japan) and Dr. Theresa Redaniel of the School of Social and Community Medicine, University of Bristol (United Kingdom) for their invaluable help and inputs especially in the statistical analysis of our data.

\section{Statement of Authorship}

All authors have approved the final version submitted.

\section{Author Disclosure}

All the authors declared no conflict of interest.

\section{Funding Source}

The authors received a grant from the Special Coordination Funds on Science and Technology Agency of the Ministry of Education, Sports, Culture, Science and Technology of Japan (JST, MEXT). Sharon Y.A.M. Villanueva received scholarship for her graduate studies from MEXT.

\section{REFERENCES}

1. Faine S, Adler B, Bolin C, Perolat P. Leptospira and Leptospirosis, 2nd ed. Melbourne, Australia: MediSci; 1999.

2. Izurieta R, Galwankar S, Clem A. Leptospirosis: the "mysterious" mimic. J Emerg Trauma Shock. 2008; 1(1):21-33.

3. World Health Organization and International Leptospirosis Society. Human leptospirosis: guidance for diagnosis, surveillance and control. Geneva: World Health Organization, 2003.

4. Levett PN. Leptospirosis. Clin Microbiol Rev. 2001; 14(2): 296-326.

5. Adler B, dela Peña Moctezuma A. Leptospira and leptospirosis. Vet Microbiol. 2010; 140(3-4): 287-96.

6. Faine S. Leptospirosis. In: Borriello SP, Murray PR, Funke G, eds. Topley and Wilson's: Microbiology and Microbial Infections. London: Hodder Arnold; 1998. pp. 1287-303. 
7. Van de Maele I, Claus A, Haesebrouck F, Daminet S. Leptospirosis in dogs; a review with emphasis on clinical aspects. Vet Rec. 2008; 163(14):409-13.

8. Zuerner RL. Laboratory maintenance of pathogenic Leptospira. Curr Protoc Microbiol. 2005; Chapter 12: Unit 12E.1.

9. Adesiyun AA, Hull-Jackson C, Mootoo N, et al. Sero-epidemiology of canine leptospirosis in Trinidad: serovars, implications for vaccination and public health. J Vet Med B Infect Dis Vet Public Health. 2006; 53(2):91-9.

10. Adesiyun AA, Hull-Jackson C, Clarke N, Whittington C, Seepersansingh N. Leptospirosis in water buffalo (Bubalus bubalis) in Trinidad. Veterinarski Arhiv. 2009; 79(1):77-86.

11. Bahaman AR, Ibrahim AL, Adam H. Serological prevalence of leptospiral infection in domestic animals in West Malaysia. Epidemiol Infect. 1987; 99(2):379-92.

12. Carlos ER, Kunden WD, Watten RH, et al. Leptospirosis in the Philippines VI. Serologic and isolation studies on carabaos. Southeast Asian J Trop Med Public Health. 1970; 1(4):481-2.

13. Geisen V, Stengel C, Brem S, Muller W, Greene C, Hartmann K. Canine leptospirosis infections - clinical signs and outcome with different suspected Leptospira serogroups (42 cases). J Small Anim Pract. 2007; 48(6):324-8.

14. Hanson LE. Bovine leptospirosis. J Dairy Sci. 1976; 59(6):1166-70.

15. O'Keefe JS, Jenner JA, Sandifer NC, Antony A, Williamson NB. A serosurvey for antibodies to Leptospira in dogs in the lower North Island of New Zealand. N Z Vet J. 2002; 50(1):23-5.

16. Basaca-Sevilla V, Cross JH, Pastrana E. Leptospirosis in the Philippines. Southeast Asian J Trop Med Public Health. 1986; 17(1):71-4

17. Bharti AR, Nally JE, Ricaldi JN, et al. Leptospirosis: a zoonotic disease of global importance. Lancet Infect Dis. 2003; 3(12):757-71.

18. Ryu E, Liu CK. Studies on the susceptibility of water buffaloes to Leptospira. Can J Comp Med. 1968; 32(2):447-9.

19. Famatiga EG. Leptospira study on fevers of unknown origin in the Philippines. Southeast Asian J Trop Med Public Health. 1971; 2(2):153-63.
20. Famatiga EG, Topacio TM, Suva MH, Oliveros FM. Studies on leptospirosis in animals and man in the Philippines V. Serological survey of leptospirosis among occupationally exposed Filipinos. Southeast Asian J Trop Med Public Health. 1972; 3:482-7.

21. Yanagihara Y, Villanueva SY, Yoshida S, Okamoto Y, Masuzawa T. Current status of leptospirosis in Japan and Philippines. Comp Immunol Microbiol Infect Dis. 2007; 30(5-6):399-413.

22. Kmety E, Dikken H. Classification of the species Leptospira interrogans and history of its serovars. Groningen: University Press; 1993.

23. Villanueva SY, Ezoe H, Baterna RA, et al. Serologic and molecular studies of Leptospira and leptospirosis among rats in the Philippines. Am J Trop Med Hyg. 2010; 82(5):889-98.

24. Songer JG, Thiermann AB. 1988. Leptospirosis. J Am Vet Med Assoc. 1988; 193(10):1250-4.

25. Lai CJ, Liu CC, Ho D, Pan MJ. Seroprevalence of Leptospira infection among stray dogs at Northern Taiwan. Taiwan Vet J. 2005; 31(1):1-8.

26. Bisa EAH. Update on the serological prevalence of bovine leptospirosis in selected cities and provinces of the Philippines (Doctor of Veterinary Medicine thesis). Los Baños, Laguna, Philippines: University of the Philippines, 1993.

27. Addamiano L, Babudieri B. Water strains of Leptospira in the serodiagnosis of human and animal leptospirosis. Bull World Health Organ. 1968; 39(6):925-34.

28. Cinco M, Dougan R. Factor analysis of saprophytic serogroups Semaranga and Andamana of Leptospira biflexa. Int J Syst Bacteriol. 1975; 25(2):138-42.

29. Wikipedia. Carabao [Online]. [cited 2010 Apr]. Available from http;// en.wikipedia.org/wiki/Carabao.

30. Masuzawa T, Dancel LA, Miyake M, Yanagihara Y. Serological analysis of human leptospirosis in the Philippines. Microbiol Immunol. 2001; 45(1):93-5. 